\title{
The Effects of a Care Program Based on the Roy Adaptation Model on Nursing Home Residents' Quality of Life
}

\author{
Masumeh Hemmati Maslakpak, ${ }^{1,}$ Esmail Maghsoodi, ${ }^{2}$ and Siyamak Sheikhi ${ }^{3}$ \\ ${ }^{1}$ Maternal and Childhood Obesity Research Center, Urmia University of Medical Sciences, Urmia, IR Iran \\ ${ }^{2}$ Department of Nursing, Faculty of Nursing and Midwifery, Urmia University of Medical Sciences, Urmia, IR Iran \\ ${ }^{3}$ Department of Psychology, Faculty of Medicine, Urmia University of Medical Sciences, Urmia, IR Iran \\ "Corresponding author: Masumeh Hemmati Maslakpak, Department of Medical-Surgical Nursing, Maternal and Childhood Obesity Research Center, Faculty of Nursing and \\ Midwifery, Urmia University of Medical Sciences, Urmia, IR Iran. Tel/Fax: +98-44132754961, E-mail: hemmatma@yahoo.com
}

Received 2015 August 31; Accepted 2015 October 10.

\begin{abstract}
Background: Different strategies are developed to improve elderly people's quality of life. One of the potentially beneficial strategies is the employment of nursing theories and models, particularly the Roy adaptation model.

Objectives: The current study aimed to investigate the effect of a care program based on the Roy adaptation model on nursing home residents' quality of life.

Methods: This quasi-experimental study was conducted on 60 residents of the nursing homes located in Urmia, Iran. The residents were conveniently selected and randomly allocated to an experimental and a control group. A demographic questionnaire and the short-form 36-item quality of life questionnaire (SF-36) were employed for data collection. The SF-36 was completed for the participants in both groups before and one month after the study intervention. A care program was developed based on the Roy adaptation model and implemented to manipulate the participants' maladaptive behaviors. The length of the study intervention was 1.5 months with a one-month follow-up period. The study data were transferred into the SPSS software. The Chi-square and the paired-and the independent-sample T-tests were employed for data analysis. Moreover, the descriptive statistics was used to present the data. P-values of less than 0.05 were considered significant.

Results: After the study, the groups differed significantly from each other in terms of the mean score of the participants' quality of life $(\mathrm{P}<0.001)$. Besides, the paired-sample T-test indicated that after implementing the study intervention, quality of life score significantly increased in the experimental group.

Conclusions: Care programs developed based on the Roy adaptation model can positively affect elderly people's quality of life. Therefore, nurses are recommended to use this model to promote the level of adaptation in the elderly people and improve their quality of life.
\end{abstract}

Keywords: Roy Adaptation Model, Quality of Life, Elderly People, Nursing Homes

\section{Background}

Aging was defined by the world health organization (WHO) as an age more than 60 years old (1). During the aging process, people usually undergo different physiological, psychological and social changes (1). Recent medical and health-related advances relatively increased humans' longevity. Consequently, aging population is increasing progressively throughout the world and even in the developing countries such as Iran (2). The rate of global population growth is $1.7 \%$ while the global aging population growth rate is $2.5 \%$. In 2011, people who aged more than 60 constituted $8.2 \%$ of the total Iranian population and it is estimated that the aging population in Iran will reach $10.5 \%$ by 2025 and $21.7 \%$ by 2050 (3).

Aging negatively affects elderly people' health and pro- gressively increases the rates of age-related problems and complications such as multiple organ dysfunctions. One of the commonest age-related complications is physical dysfunction which undermines elderly people's independence and enhances their need for help (4). Given the debilitating complications of aging, care-related activities and strategies should pay a special attention to elderly people's quality of life (QOL). Healthcare measures for elderly people are considered effective provided that they improve QOL. Currently, the concept of active aging is introduced which denotes that the aim of supportive measures for elderly people should not be merely to increase their life expectancy; rather, healthcare services should focus on improving their QOL as well (5).

As a key health-related concept, QOL is highly valued by international organizations such as WHO. This organi-

Copyright ( 2015 , Birjand University of Medical Sciences. This is an open-access article distributed under the terms of the Creative Commons Attribution-NonCommercial 4.0 International License (http://creativecommons.org/licenses/by-nc/4.0/) which permits copy and redistribute the material just in noncommercial usages, provided the original work is properly cited. 
zation defined QOL as "individuals' perception of their position in life in the context of the culture and value systems in which they live and in relation to their goals, expectations, standards, and concerns" (6). Alongside with progressive increase in aging population, improvement of elderly people's QOL is also received an international attention $(4,6)$. Therefore, many studies focused on factors which affect QOL including health, family, interpersonal relationships, role performance and recreational activities $(7,8)$. The most critical factor behind elderly people's QOL is their health (9). QOL has different aspects grouped into three closely-interrelated main categories of physical, psychological and social (10). Improving elderly people's QOL and modifying their lifestyles can considerably promote their independence and efficacy and help them effectively manage their age-related complications and problems (11).

Age-related physical and mental health problems reduce elderly people's QOL and limit their ability to adapt to aging. These problems are manifested in unhealthy and maladaptive behaviors. Accordingly, healthcare measures are needed to change elderly people's unhealthy and maladaptive behaviors to healthy and adaptive ones (12). To facilitate behavior modification, healthcare professionals can use adaptation-related theories, particularly the Roy adaptation model (RAM) (13).

In her theory, Roy considered an individual as a comprehensive set which consists of physical (physiological) and psychological (self-concept, role function and interdependence) domains. Thus, holistic adaptation occurs once a person achieves adaptation in these two domains or four modes (14). According to Roy, adaptation is affected by three main stimuli including focal, contextual, and residual. Therefore, adaptation can be promoted through manipulating these stimuli during the process of care delivery. The main reasons behind clients' maladaptive behaviors (i.e. focal, contextual and residual stimuli) can be identified through assessing clients' physiological, selfconcept, role function and interdependence modes. Such an assessment helps to develop more effective programs to modify clients' maladaptive behaviors (15).

QOL consists of both physiological and psychological aspects while RAM can comprehensively cover these aspects and produce positive outcomes for the elderly people (12). Therefore, using standard care delivery models such as RAM seems necessary. RAM is a safe, non-invasive, inexpensive, easily applicable non-pharmacological intervention to enhance individuals' physical and psychological adaptation (13).

\section{Objectives}

The current study aimed to investigate the effect of an RAM-based care plan on nursing home residents' QOL.

\section{Methods}

The study was conducted in 2013 by following a pretestposttest controlled quasi-experimental design. The study population was the residents of the nursing homes located in Urmia, Iran. All 60 eligible elderly people were conveniently recruited. They were included if they were 60 years old or more (1), oriented to time, place and person, did not receive psychotherapy or experience the loss of close relatives during the last six months before the study, did not receive treatments which could affect mental abilities, memory, or thinking, and did not have hearing or speech impairment, debilitating conditions, and physical disorders which could affect mental health (such as thyroid disorders). On the other hand, those participants who experienced any significant negative event or death were excluded from the study. After obtaining a written informed consent from the subjects, they were randomly allocated to an experimental or a control group using randomization software.

A demographic questionnaire and the Persian version of the short-form 36-item QOL questionnaire (SF-36) were employed for data collection (11). The questionnaires were completed for the participants through the interview technique. The SF-36 is a valid and reliable questionnaire which contains 36 questions and assesses QOL in eight domains including physical functioning, role performance, bodily pain, general health perception, vitality, social functioning, emotional functioning and mental health. Three-, fiveand six-choice questions of the SF-36 are scored on three-, five-, and six-point scales of ' 0,50 and 100', '0, 25, 50, 75, and 100 ', and ' $0,20,40,60,80$, and 100', respectively. Therefore, the total score of each domain ranges from 0 to 100 , the higher the score the better the QOL. The validity and the reliability of the SF-36 were evaluated in different studies. For example, Heidari and Shahbazi found that the Cronbach's alpha and the test-retest correlation coefficient of the survey were 0.83 and 0.87 , respectively (16). Hamidizadeh et al. also confirmed the content validity of the SF-36 and reported a test-retest correlation coefficient of 0.87 (17). Montazeri et al. also noted that the SF-36 had an acceptable validity and reliability (18).

To design the study intervention, authors initially assessed and identified each participant's physiological, selfconcept, role function and interdependence maladaptive behaviors and their focal, contextual and residual stimuli through the standardized RAM-based assessment forms. 
The forms were completed by holding personal interviews with each participant. Then, a unique four-session care plan was developed and implemented for each participant based on his/her maladaptive behaviors and their focal, contextual and residual stimuli. The plans aimed to modify unhealthy and maladaptive behaviors and turn them into healthy and adaptive ones. Besides these four-session individual care plans, two educational sessions were held for all participants to address their joint maladaptive behaviors. For instance, educations in the area of physiological behaviors were about proper nutrition, adequate and balanced physical activity, factors affecting sleep, etc. Regarding the self-concept mode, educations were provided to make positive changes in the participants' self-image and ideal image. In the interdependence mode, educations were mainly about peer relations and participation in group discussions and religious rituals. Finally, educations in role function mode included materials such as assuming some responsibilities in nursing homes, participating in their birthday or wedding parties and organizing and joining sport teams. To prevent information leakage from the participants in the experimental group to their counterparts in the control group, the administrators of the nursing homes settled them in separate rooms.

In the four-session personal programs, it was attempted to manipulate the focal, contextual and residual stimuli of each individual participant's physiological, selfconcept, role function and interdependence maladaptive behaviors. For instance, a participant with muscular weakness (a physiological problem) due to limited mobility (the focal stimulus) was encouraged to do physical exercise and walk. Besides, such participants were accompanied in their physical exercises. On the other hand, a participant with constipation (a physiological problem) due to limited intake of fluids and high-fiber foods (the focal stimuli) and decreased physical activity (the contextual stimulus), was provided with fruits, vegetables and fluids and was asked to perform physical activity. Finally, the elderly participants with role function and interdependence-related maladaptive behaviors were provided with counseling services by a psychologist.

During the first one month period after implementing the intervention, authors referred to the study setting and supervised the participants' engagement in behavior modification activities. At the end of this onemonth follow-up period, the participants were asked to recomplete the SF-36. For the sake of ethical considerations, the care plans were provided to the administrators and the staffs of the study setting and they were asked to use them for the participants in the control group.

One participant from the experimental group died during the study and thus, the number of elderly people in this group reduced to 29 . The study data were transferred into the SPSS software. The descriptive statistics was used to present the data while the Chi-square and the pairedand the independent-sample T-tests were employed for data analysis. P-values less than 0.05 were considered as significant.

\section{Results}

The independent-sample T-test and the Chi-square test showed insignificant differences between the experimental and the control groups respecting the participants' age, length of stay in nursing homes, number of children, gender, marital and educational status, source of income and insurance coverage (Table 1 ).

The results of the study also revealed that the groups did not differ significantly concerning the pretest mean scores of physical functioning, role performance, bodily pain, general health perception, vitality, social functioning, emotional functioning and mental health as well as total QOL mean score ( $\mathrm{P}>0.05)$. However, in the posttest, the differences between the groups regarding all these variables were statistically significant $(\mathrm{P}<0.05$; Table 2$)$.

The pretest and the posttest mean scores of QOL in the control group were 43.49 and 43.69 , respectively. In the experimental group, the pretest QOL mean score was 46.36 which increased to 67.59 after the study intervention. The paired-sample T-test results indicated that pretest-posttest difference in the score of QOL in the control group was not statistically significant $(\mathrm{P}=0.354)$, while it was significant in the experimental group $(\mathrm{P}<0.001)$ (Table 3$)$.

\section{Discussion}

One of the challenges of the 21st century is to promote people's independence, self-control and adaptation to new life situations. Achieving these goals necessitates developing and implementing care plans based on RAM (14).

The study findings showed that the participants' QOL was moderate to low and the study groups did not differ significantly in terms of the pretest mean scores of QOL. QOL is the difference between humans' expectations and realities; the smaller the difference, the higher the QOL. Therefore, QOL is totally a personal matter which is based on individuals' own perceptions of the different aspects of their lives; hence, it cannot be directly observed by others (19). Chan et al. reported that the most significant predictor of QOL was health, undermined by age (9). Osada also noted that elderly people who were able to do physical, recreational, leisure-time and daily life activities experienced lower levels of depression and had higher QOL 


\begin{tabular}{|c|c|c|c|c|c|}
\hline \multirow[t]{2}{*}{ Variable } & \multirow{2}{*}{$\begin{array}{l}\text { Control } \\
\text { Group }\end{array}$} & \multirow{2}{*}{$\begin{array}{l}\text { Experimental } \\
\text { Group }\end{array}$} & \multicolumn{3}{|c|}{ Independent-Sample T-Test and Chi-Square Results } \\
\hline & & & $\mathrm{X}^{2}$ & df & P Value \\
\hline Age & $70.1 \pm 4.95$ & $69.58 \pm 7.03$ & & & 0.778 \\
\hline $\begin{array}{l}\text { Length of stay in nursing } \\
\text { homes }\end{array}$ & $5.5 \pm 2.35$ & $5.79 \pm 2.11$ & & & 0.617 \\
\hline Number of children & $3.83 \pm 1.53$ & $3.62 \pm 1.98$ & & & 0.647 \\
\hline Gender & & & 0.316 & 1 & 0.574 \\
\hline Female & $28(93.34)$ & $28(96.55)$ & & & \\
\hline Male & $2(6.66)$ & $1(3.45)$ & & & \\
\hline Marital status & & & 3.783 & 3 & 0.414 \\
\hline Married & $6(20)$ & $8(27.59)$ & & & \\
\hline Single & 0 & $2(6.9)$ & & & 0 \\
\hline Divorced & $1(3.34)$ & 0 & & & \\
\hline Spouse's death & $23(76.66)$ & $19(65.5)$ & & & \\
\hline Nursing homes & & & 0.126 & 3 & 0.989 \\
\hline Khaneye-Sabz & $16(53.34)$ & $16(55.16)$ & & & \\
\hline Al-Zahra & $7(23.34)$ & $7(24.16)$ & & & \\
\hline Ferdows & $4(13.32)$ & $3(10.34)$ & & & \\
\hline Araa & $3(10)$ & $3(10.34)$ & & & \\
\hline Educational status & & & 0.269 & 22 & 0.874 \\
\hline Illiterate & $18(60)$ & $19(65.5)$ & & & \\
\hline $\begin{array}{l}\text { Under high school } \\
\text { diploma }\end{array}$ & $9(30)$ & $8(27.6)$ & & & \\
\hline $\begin{array}{l}\text { High School diploma } \\
\text { and higher }\end{array}$ & $3(10)$ & $2(6.9)$ & & & \\
\hline Source of income & & & 3.913 & 24 & 0.418 \\
\hline Charities & $5(16.6)$ & $6(20.6)$ & & & \\
\hline Family & $8(26.7)$ & $8(27.6)$ & & & \\
\hline Personal income & $17(56.7)$ & $15(51.8)$ & & & \\
\hline Insurance coverage & & & 0.576 & 21 & 0.451 \\
\hline Yes & $26(86.7)$ & $23(79.3)$ & & & \\
\hline No & $4(13.3)$ & $6(20.7)$ & & & \\
\hline
\end{tabular}

${ }^{\mathrm{a}}$ Values are expressed as mean \pm SD or No. (\%).

(20). Subasi and Hayran found that elderly people with adequate leisure time and greater ability to perform activities of daily life were more satisfied with their lives. They also reported that educational and marital statuses, as well as leisure-time activities, significantly affect QOL (21).

The study findings also revealed the positive effects of the implemented RAM-based care program on elderly people's QOL. QOL consists of physical, psychological and social domains. On the other hand, RAM also considers human as a comprehensive existence that has physical, psychological and social aspects (14). Consequently, RAMbased programs are usually comprehensive enough, cover humans' different existential aspects and positively affect QOL. In agreement with the current study findings, Bakan and Akyol implemented RAM-based care program for patients with heart failure and found that it significantly im- proved their adaptations in the four main modes of physiological, self-concept, role function and interdependence (22). Besides, Rogers et al. reported the positive effects of physical activity on elderly people's physiological adaptation. Nonetheless, they found that physical activity was not effective in promoting self-concept adaptation (12). The results of a study conducted in Iran by Sadeghnezhad et al. also illustrated that a ten-session RAM-based educational program with a one-month follow-up period significantly promoted psychological adaptation of patients with diabetes mellitus (23).

The findings of the present study also revealed that the implemented RAM-based care program significantly improved the scores of the different domains of QOL including physical functioning, role performance, bodily pain, general health perception, vitality, social func- 
Table 2. Comparing the Experimental and the Control Groups Based on the Mean Scores of QOL Domains

\begin{tabular}{|c|c|c|c|c|c|c|}
\hline \multirow[t]{2}{*}{ Time } & \multicolumn{2}{|c|}{ Before } & \multirow{2}{*}{$\begin{array}{c}\text { Independent- } \\
\text { Sample } \\
\text { T-Test }\end{array}$} & \multicolumn{2}{|c|}{ After } & \multirow{2}{*}{$\begin{array}{c}\text { Independent- } \\
\text { Sample } \\
\text { T-Test }\end{array}$} \\
\hline & $\begin{array}{c}\text { Experimental } \\
\text { Group }\end{array}$ & Control Group & & $\begin{array}{l}\text { Experimental } \\
\text { Group }\end{array}$ & Control Group & \\
\hline $\begin{array}{l}\text { Physical } \\
\text { functioning }\end{array}$ & $20.64 \pm 47.24$ & $21.52 \pm 37.33$ & 0.077 & $20.42 \pm 69.31$ & $20.96 \pm 36.33$ & $0.001>$ \\
\hline Role performance & $14.41 \pm 56.03$ & $21.10 \pm 41.64$ & 0.05 & $16.27 \pm 73.27$ & $25.72 \pm 47.50$ & $0.001>$ \\
\hline Bodily pain & $15.65 \pm 50.60$ & $20.75 \pm 42.08$ & 0.081 & $12.16 \pm 81.12$ & $18.67 \pm 38.58$ & $0.001>$ \\
\hline $\begin{array}{l}\text { General health } \\
\text { perception }\end{array}$ & $4.90 \pm 45.17$ & $9.00 \pm 45.00$ & 0.928 & $6.99 \pm 60.51$ & $8.21 \pm 44.91$ & $0.001>$ \\
\hline Vitality & $9.31 \pm 52.41$ & $12.08 \pm 52.16$ & 0.93 & $7.13 \pm 64.82$ & $9.69 \pm 52.08$ & $0.001>$ \\
\hline Social functioning & $12.27 \pm 49.63$ & $14.28 \pm 46.66$ & 0.06 & $10.86 \pm 68.10$ & $14.28 \pm 44.75$ & $0.001>$ \\
\hline $\begin{array}{l}\text { Emotional } \\
\text { functioning }\end{array}$ & $18.93 \pm 47.12$ & $18.94 \pm 52.21$ & 0.269 & $14.03 \pm 67.81$ & $29.98 \pm 48.88$ & $0.005>$ \\
\hline $\begin{array}{l}\text { Psychological } \\
\text { health }\end{array}$ & $8.36 \pm 56.48$ & $9.34 \pm 54.43$ & 0.379 & $8.54 \pm 66.06$ & $6.18 \pm 52.73$ & $0.001>$ \\
\hline QOL & $3.80 \pm 46.36$ & $10.03 \pm 43.49$ & 0.156 & $6.39 \pm 67.59$ & $10.21 \pm 43.69$ & $0.001>$ \\
\hline
\end{tabular}

Abbreviation: QOL, quality of life.

Table 3. Pretest-Posttest Intergroup Comparison of Total QOL Score ${ }^{a}$

\begin{tabular}{lccc}
\hline QOL & Before & After & Paired-Sample T-Test \\
\hline Control group & $10.03 \pm 43.49$ & $10.21 \pm 43.69$ & 0.354 \\
Experimental group & $3.80 \pm 46.36$ & $6.39 \pm 67.59$ & $0.001>$ \\
\hline
\end{tabular}

Abbreviation: QOL, quality of life.

${ }^{\mathrm{a}}$ Values are expressed as mean $\pm \mathrm{SD}$

tioning, emotional functioning and mental health. The strongest effect of the intervention was on elderly people's bodily pain domain of QOL, denoting significant decrease in the participants' problems in the area of bodily pain. This finding can be attributed to the effectiveness of the study intervention in boosting the participants' physical strength and stimulating their desire to do more intense physical activities. On the other hand, the increase in the score of the psychological domain of QOL was smaller than those of the other domains. This finding is probably due to the closed environment of nursing homes as well as nursing home residents' separation from their families. In line with the current study findings, Li et al. found that percutaneous coronary intervention was more effective than medication therapy to improve the scores of the physical functioning, bodily pain, physical role performance and general health domains of QOL among elderly people with acute coronary syndrome (24). Shyu et al. also reported that their interdisciplinary intervention significantly increased the scores of the physical domains of QOL among the elderly patients who had undergone a hipfracture surgery (25). Imayama et al. compared the effects of dietary weight loss and exercise interventions on QOL in females with overweight and obesity. They found that dietary weight loss intervention was as effective as exercise intervention to improve the scores of the physical domains of QOL while combined dietary weight loss and exercise interventions produced more significant effects (26). In addition, Yu et al. indicated the efficiency of vitrectomy on the improvement of different aspects of QOL (including physical functioning, role performance, general health, social functioning, emotional functioning and psychological health) among patients with diabetic retinopathy (27). Dickson et al. a based on a study in New York reported that the self-care program and exercise-based intervention, as well as elderly people's engagement in workrelated activities, significantly enhanced physical and total QOL (28). The results of studies conducted in Iran also showed that elderly people's QOL can be significantly improved through administrating educational interventions (26), group physical activity programs (17) and self-care programs $(7,29)$.

Families had a significant role in providing care to elderly people and patients with chronic illnesses. Unfortunately, the physical distance between families and nursing homes deprives nursing home residents from their families' kindness, intimacy and support; hence, it can negatively affect their QOL. 


\subsection{Conclusions}

According to the findings of the study, RAM-based care programs can improve QOL among elderly residents of nursing homes. Care plans and programs developed based on RAM and elderly people's needs can encourage elderly people's participation in healthy behaviors, promote their adaptation to aging and produce positive QOL-related results.

\section{Acknowledgments}

The present article was extracted from a Master's thesis approved by the research council of Urmia University of Medical Sciences, Urmia, Iran. The registration and the ethical approval codes of the study were IRUMSU.REC1393.32 and 92011331273. The authors would like to thank the elderly people and the administrators of nursing homes in Urmia, Iran, for their participation in the study.

\section{References}

1. United Nations . World Population Ageing 2013 2013. Available from: http://www.un.org/en/development/desa/population/publications/ pdf/ageing/WorldPopulationAgeing2013.pdf.

2. Mirzaiee M, Shams-ghahfarokhi M. The Aged demographic Information based on 1956-2006 censuses in Iran. Iran JElderly. 2007;2(5):32631.

3. Taheri P. Aging population report. Tehran: Ministry of Health and Medical Education; 2013.

4. Hasan-poordehbokri A, Masoodi R, Naderipoor A, Pormirza-kalhori R. The effects of exercise on quality of life of elderly people in Shahrekord city. Iran J Elderly. 2007;2(6):437-44.

5. Hutchinson A, Rasekaba TM, Graco M, Berlowitz DJ, Hawthorne G, Lim WK. Relationship between health-related quality of life, and acute care re-admissions and survival in older adults with chronic illness. Health Qual Life Outcomes. 2013;11:136. doi: 10.1186/1477-7525-11-136. [PubMed: 23919897].

6. World Health Organization . WHOQOL-BREF: introduction, administration, scoring and generic version of the assessment : field trial version, 1996. Available from: http://apps.who.int/iris/bitstream/10665/ 63529/1/WHOQOL-BREF.pdf.

7. Mirsaeidi Z, Eftekhar-Ardabili H, Nouri K. Effect of a self-care program on quality of life of the elderly clients covered by health centers of Southern of Tehran. Sci J School Public Health Inst Public Health Res. 2012;10(4):17-32.

8. Salar AR, Ahmadi F, Faghihzadeh S. Study of effectiveness of continuous care consultation on the quality of life of elderly clients. Zahedan J Res Med Sci. 2004;5(4):261-7.

9. Chan KM, Pang WS, Ee CH, Ding YY, Choo P. Self-perception of health among elderly community dwellers in Singapore. Ann Acad Med Singapore. 1998;27(4):461-7. [PubMed: 9791647].

10. King CR, Hinds PS. Quality of life: from nursing and patient perspectives. Jones \& Bartlett Publishers; 2011.

11. Darvishpoor Kakhki A, Abed Saeedi J, Delavar A. Tools for measurement of health status and quality of life of elderly people. Res Med. 2010;33(3):162-73.
12. Rogers CE, Keller C, Larkey LK, Ainsworth BE. A randomized controlled trial to determine the efficacy of Sign Chi Do exercise on adaptation to aging. Res Gerontol Nurs. 2012;5(2):101-13. doi: 10.3928/1940492120110706-01. [PubMed: 21751770].

13. Chiou CP. A meta-analysis of the interrelationships between the modes in Roy's adaptation model. Nurs Sci Q. 2000;13(3):252-8. [PubMed: 11847806].

14. Sharif F, Mohebbi S, Tabatabaee HR, Saberi-Firoozi M, Gholamzadeh S Effects of psycho-educational intervention on health-related quality of life (QOL) of patients with chronic liver disease referring to Shiraz University of Medical Sciences. Health Qual Life Outcomes. 2005;3:81. doi: 10.1186/1477-7525-3-81. [PubMed: 16356186].

15. Rich F. Learning Disability Nursing, Roy's Adaptation Model of Nursing Birmingham City University; 2010. Available from shareville.bcu.ac.uk/index.php?q=system/.../bcu_version_roys_ adaptation_model.pdf.

16. Heidari M, Shahbazi S. Effect of self-care training program on quality of life of elders. Iran J Nurs. 2012;25(75):1-8.

17. Hamidizadeh S, Ahmadi F, Aslani Y, Etemadifar SH, Salehi K, Kord Y Study effect of a group-based exercise program on the quality of life in older men and women in 2006-2007. J Shaheed Sadoughi Univ Med Sci. 2007;16(1):81-6

18. Montazeri A, Goshtasebi A, Vahdaninia M, Gandek B. The Short Form Health Survey (SF-36): translation and validation study of the Iranian version. Qual Life Res. 2005;14(3):875-82.

19. Basakha M, Kohneshahri LA, Masaeli A. Ranking the quality of life in Iran provinces. Soc Welfare Q. 2010;10(37):95-112.

20. Osada $\mathrm{H}$, Shibata $\mathrm{H}$, Haga $\mathrm{H}$, Yasumura S. [Relationship of physical condition and functional capacity to depressive status in person aged 75 years]. Nihon Koshu Eisei Zasshi. 1995;42(10):897-909. [PubMed: 8520045].

21. Subasi F, Hayran O. Evaluation of life satisfaction index of the elderly people living in nursing homes. Arch Gerontol Geriatr. 2005;41(1):23-9. doi:10.1016/j.archger.2004.10.005. [PubMed: 15911035].

22. Bakan G, Akyol AD. Theory-guided interventions for adaptation to heart failure. J Adv Nurs. 2008;61(6):596-608. doi: 10.1111/j.13652648.2007.04489.x. [PubMed: 18302601].

23. Sadeghnezhad M, Vanaki Z, Memarian R. The effect of nursing care plan based on "Roy's adaptation model" on physiological adaptation in patients with type II diabetes. Daneshvar Med. 2011;18(92):1-11.

24. Li R, Yan BP, Dong M, Zhang Q, Yip GW, Chan CP, et al. Quality of life after percutaneous coronary intervention in the elderly with acute coronary syndrome. Int J Cardiol. 2012;155(1):90-6. doi: 10.1016/j.ijcard.2010.09.050. [PubMed: 20965591].

25. Shyu YI, Liang J, Wu CC, Cheng HS, Chen MC. An interdisciplinary intervention for older Taiwanese patients after surgery for hip fracture improves health-related quality of life. BMC Musculoskelet Disord. 2010;11:225. doi: 10.1186/1471-2474-11-225. [PubMed: 20920220].

26. Imayama I, Alfano CM, Kong A, Foster-Schubert KE, Bain CE, Xiao L, et al. Dietary weight loss and exercise interventions effects on quality of life in overweight/obese postmenopausal women: a randomized controlled trial. Int J Behav Nutr Phys Act. 2011;8:118. doi: 10.1186/14795868-8-118. [PubMed: 22026966].

27. Yu Y, Feng L, Shao Y, Tu P, Wu HP, Ding X, et al. Quality of life and emotional change for middle-aged and elderly patients with diabetic retinopathy. Int J Ophthalmol. 2013;6(1):71-4. doi: 10.3980/j.issn.2222 3959.2013.01.15. [PubMed: 23549357].

28. Dickson VV, Howe A, Deal J, McCarthy MM. The relationship of work, self-care, and quality of life in a sample of older working adults with cardiovascular disease. Heart Lung. 2012;41(1):5-14. doi: 10.1016/j.hrtlng.2011.09.012. [PubMed: 22079043].

29. Baraz S, Rostami M, Farzianpor F, Rasekh A. Effect of Orem Self Care Model on ederies' quality of life in health care centers of Masjed Solaiman in 2007-2008. Arak Med Univ J. 2009;12(2):51-9. 